\title{
La utopía y la dialéctica vital de la Biblia como característica esencial de la mentalidad de S. Agustín
}

\section{Introducción: Esperanza, Utopía, Dialéctica vital}

En las siguientes páginas me propongo hacer algunas reflexiones sobre una de las características fundamentales de la personalidad y de la doctrina de S. Agustín, cuyo olvido o tergiversación ha traído muy graves consecuencias de todo tipo en el transcurso de los siglos tanto en el campo teológico como en el político. La pérdida de su visión dinámica, utópica y escatológica de la perfección cristiana de la persona, de la vida de la Iglesia y de la sociedad en general ha producido un sinfín de problemas y de escisiones en la Iglesia así como una justificación del mal llamado «agustinismo político» de la Edad Media con la gran adulteración evangélica del poder temporal de los papas o «teoría de las dos espadas o dos banderas». Pero antes es preciso recordar brevemente la relación íntima entre los diversos elementos que constituyen esa mentalidad, es decir: la esperanza; la utopía o utopías evangélicas y la dialéctica vital.

Es de agradecer a ciertas corrientes filosóficas modernas, como la llamada «escuela crítica neo-marxista de Frankfurt», su insistencia en proponernos la esperanza como un elemento constitutivo de la persona humana. Ernst Bloch, el cantor por excelencia de la esperanza, nos definne al hombre como un ser que aspira y espera, siendo de este modo «junto con el mundo que le rodea, una tarea y un gigantesco receptáculo lleno de futuro» ${ }^{~}$. Para él, la ąngustia, contra lo que defendían los existencialistas J.P. Sartre, A. Camus, etc., no es un elemento constitutivo de la existencia humana, sino más bien el sentimiento que brota en el hombre ante su esperanza amenazada. De ahí que

1. E. BLoch, Das Prinzip Hoffnung, Frankfurt a.M., 1959, 135. 
la esperanza no sea para $\mathrm{E}$. Bloch un «espacio hueco», sino más bien la fuente de la utopía, como fuerza motriz que impulsa la acción comprometida para el cambio social en la historia dentro de esa dialéctica de choque fecundo entre la realidad con sus limitaciones y la utopía anhelada, entre el «ya-pero todavía no» ${ }^{2}$.

No en vano todos los filósofos de la escuela de Frankfurt: M. Horkheimer, T. Adorno, E. Bloch, H. Marcuse, E. Fromm, J. Habermas, son de origen judío y, por lo mismo, llevan en su entraña la mentalidad dinámica y utópica de la Biblia, si bien ellos se limitan en general a una esperanza y utopía intramundanas en la línea del comunismo ideal y nunca definido de Carlos Marx ${ }^{3}$. Pero han contribuido sin duda a remover nuestra conciencia de cristianos, a veces en exceso dormida y amodorrada por la rutina, impulsándonos a releer el Evangelio en el marco de esa mentalidad semita en que fue escrito, y a descubrir la vida y el mensaje reales de Jesús en toda su fuerza y extensión liberadoras. La teología de la esperanza, iniciada por el teólogo luterano J. Moltmann, la teología política del teólogo católico J.B. Metz y la llamada «teología latino-americana de la liberación» deben mucho a esos filósofos humanistas de la esperanza, del mismo modo que la insistencia de L. Feuerbach en proponer la caridad social como el elemento esencial y más puro de la esencia humana contribuyó de un modo notable a que los teólogos cristianos (desde Karl Adam a A. von Harnack) se empeñaran en serio en redescubrir la caridad como la esencia del cristianismo. Son los «signos de los tiempos», de que hablara Juan XXIII como clave del Vaticano II, viendo la obra del Creador en la creatividad fecunda de los hombres.

Pues bien; si contemplamos el panorama inmenso de la Biblia como historia de salvación de la persona y de la humanidad, y si no nos empeñamos en destruir en Agustín esa misma visión histórica y dinámica de la salvación en la cual no hay escisión entre la fe y la razón, entre teología y filosofía, sino más bien una relación dialéctica de plenitud por parte del gran don de la fe, veremos que esos tres elementos ya mencionados constituyen una unidad inquebrantable en esta vida de peregrinos: la esperanza o búsqueda esperanzada de la felicidad plena, que en el cristianismo recibe todo su sentido de Jesucristo, muerto en la cruz y resucitado por amor nuestro; la utopía de ese seguimiento de Cristo en la resurrección con las implicaciones que tiene para la vida y la perfección humanas en todos los sentidos, como fuerza motriz y luz que ilumina el camino de la esperanza; y la dialéctica vital en medio de la cual se mueve nuestra esperanza utópica durante toda la vida de la persona y de la sociedad,

2. E. BLOCH, o.c., 152ss.

3. Cfr. W. KERN, Atheismus, Marxismus, Christentum. Beiträge zur Diskussion, Innsbruck-Wien-München 1976. 
es decir, la lucha o desorden (S. Pablo la llama hamartía o fuente del pecado) entre la tendencia radical al bien, al amor, a la justicia, y también la tendencia radical al egoísmo, al mal, a la injusticia. Los bienes de nuestra naturaleza humana, tan decantados por el mismo Agustín en el último libro de «La Ciudad de Dios», se ven combatidos interior y exteriormente por las limitaciones de nuestra finitud, de nuestro instinto de conservación, del impulso de todo ser libre a constituirse en principio y fin de sí mismo, cuando en realidad se sabe de antemano que eso es imposible. Ésa es la realidad humana descrita en la Biblia con el relato mítico del pecado de Adán y Eva en el paraíso, y que S. Pablo tomó como historia, dando origen a esa antropología teológica del pecado original que debemos superar de un modo absoluto, y que Agustín no inventó, sino que se limitó a tratar de exponer el modo de su transmisión por la generación con la concupiscencia 4 .

No perdamos, pues, de vista al interpretar a S. Agustín esa relación íntima entre esperanza, utopía y dialéctica vital, si queremos evitar un sinfín de adulteraciones de su pensamiento, y lo que es más grave, si queremos evitar una adulteración muy seria del Evangelio, tanto por defecto como por exceso en sus exigencias y contenidos.

Algunos sociólogos y filósofos modernos hacen una crítica casi despiadada de los defectos de la Iglesia en cuanto institución en el transcurso de los siglos, llegando incluso a acusar a S. Pablo de servilismo y de conformismo político ante las estructuras sociales de su tiempo y tachando a S. Lucas, por su doctrina del Reino, de verdadero preparador de la «era constantiniana» ${ }^{5}$. Otros autores siguen acusando a S. Agustín de un sinfín de responsabilidades en lo tocante al mal llamado «agustinismo político» de la Edad Media, al pesimismo humanista por su antropología como «dialéctica vital» ya menciona$\mathrm{da}$, a ciertos rigorismos en lo referente al matrimonio, a falta de oposición clara y eficaz a ciertas estructuras del derecho romano, como la esclavitud, etc. Pero todo ello queda desenfocado por no tener presente al interpretarlos la «hermenéutica de las culturas y de los géneros literarios» -i isobre todo de las culturas!-, la cual nos descubre que, si bien la cultura greco-romana y su

4. Ver una amplia exposición de esta cuestión en A. TuRrado, La antropología de S. Agustín en la polémica antipelagiana. Su lectura después del Vaticano II, en «Obras Completas de S. Agustín», BAC, t. XXXV, Madrid 1984.

5. Cfr. A. MAYER, Der zensierte Jesus. Soziologie des Neuen Testaments, Olten-Freiburg i.Br. 1983; ver las anotaciones de N. Greinacher en el prólogo, pp. 7-9; una visión totalmente agnóstica del origen del cristianismo por G. PuENTE OJEA, Ideología e Historia. La formación del cristianismo como fenómeno ideologico, Madrid $1984^{3}$ : como si todo hubiera sido una pura lucha sociológica por el poder. 
concepción estática del mundo favorecía un ambiente de aceptación de las instituciones sociales y políticas, sin embargo, tanto S. Pablo como S. Agustín realizaron cambios muy profundos al poner el amor social y la fraternidad universal del Evangelio como la única relación posible entre los cristianos de todas las condiciones sociales. De esto hablaremos más adelante.

Esa «hermenéutica de las culturas» no debe servirnos para justificar desde hoy todo lo pasado, pero sí para comprenderlo mejor y para valorar también sus inmensos logros. De lo contrario, «la cotidianeidad o domesticación del carisma» de que hablaba Max Weber bajo un punto de vista agnóstico se quedará muy suave en comparación con esas acusaciones, tan apodícticas como miopes, contra el cristianismo.

Una visión panorámica de esa mentalidad utópica y dialéctica vital de la Biblia nos hará comprender mejor el alcance del mensaje que nos legó S. Agustín en su vida y en sus escritos.

La mentalidad semita de la Biblia constituye un mundo muy diverso del que la cultura greco-romana nos ha transmitido a las naciones de Europa. Se trata de una mentalidad dinámica, funcional e histórica, en la que no existe el verbo ser en el sentido esencialista griego como definición de las cosas.o especies. Su noción del ser-en-acción (hayāh), como un «estar-siendo y haciéndose ahí», concibe al hombre como un soplo de Dios (nephes) que vivifica el polvo y constituye así a la persona visible (basār), que es libre y responsable de sus actos ante Dios. En esa mentalidad dinámica y funcional, por la cual comienzan a hablar de las cosas cuando ellos las perciben (teología de epifanía o manifestación), la esperanza en la utopía final o triunfo definitivo del bien sobre el mal es la fuerza que mueve a la humanidad, si bien los caminos de esa historia son esencialmente una dialéctica vital o lucha personal y social entre el bien y el mal ${ }^{6}$. Ésa es la realidad que la Biblia nos relata desde la descripción mítica de la creación y del drama del paraíso terrenal, cuando sitúa al comienzo de la historia humana la felicidad plena que el hombre espera sin cesar, cuando trata de explicar por el pecado de Adán y Eva el origen de todos los males y de la muerte debido al orgullo y a la divinización del hombre (iseréis iguales a Dios!), cuando en el Nuevo Testamento se nos habla de los convertidos por el seguimientỏ de Cristo (metánoia: cambio de vida) y de los no convertidos como personificación del fin que espera a unos y a otros en el juicio final (Mt 25), cuando S. Pablo vuelve a tomar la dialéctica del hombre nuevo y del hombre viejo en relación con el Adán terreno y con el Cristo celestial, y en fin

6. Cfr. T. Boman, Hebrew Thought Compared with Greek, London 1960; E. JACOB, Teología del Antiguo Testamento, Madrid 1969, 150ss.; H. Wolf, Antropología del Antiguo Testamento, Salamanca 1975. 
cuando S. Juan contempla la historia humana como una lucha entre Cristo y el Anticristo con el triunfo definitivo del Kýrios o Señor esperado. Si no se comprende esta mentalidad dinámica bíblica, precisamente del todo opuesta al maniqueísmo, porque es el hombre, y no un principio eterno del mal, el responsable de su vida, será imposible comprender rectamente los dos amores y las dos ciudades de que nos habla S. Agustín en su célebre obra apologética $L a$ Ciudad de Dios.

Vuelvo a repetir que esa relación dialéctica y, por lo tanto inseparable durante esta vida terrenal, entre la esperanza y la utopía o felicidad plena, cuyo modelo supremo es el Dios-Amor manifestado en Cristo, y la lucha personal y social (dialéctica vital) durante el tiempo de acción y de espera, es un elemento esencial para comprender la doctrina de S. Agustín en sus ejes fundamentales, es decir: la utopía de la «verdadera libertad» y el diálogo de la gracia; la utopía de Cristo "Sacramento del amor de Dios y nuestro único ejemplo» y el sentido escatológico de nuestra perfección cristiana y de la vida de la Iglesia; la utopía de la «única verdadera justicia y verdadera república» y el sentido escatológico de todos los modelos de sociedad.

Sin duda esa mentalidad dialéctica y utópica o escatológica tiene en Agustín un cierto tinte neoplatónico cristianizado, debido a la idea de creación como participación gradual de las perfecciones de Dios ${ }^{7}$; participación que implica a su vez las nociones, en buena parte bíblicas, de eficiencia, ejemplaridad y presencia del Supremo Ejemplar en todas sus obras. También es obvio que esa mentalidad neoplatónico-cristiana lleva a Agustín, al igual que antes lo hicieran Orígenes y S. Ambrosio, a una exégesis bíblica preferentemente alegórica y mística, que los impulsa a buscar en la Biblia el sentido espiritual del seguimiento de Cristo y de la unión más perfecta posible con Dios; mientras que los aristotélicos de la escuela antioquena, como Teodoro de Mopsuestia y sus simpatizantes latinos Pelagio y Julián de Eclana, tratan de buscar más bien el sentido literal con no pocas contradicciones ${ }^{8}$. Reducir, como lo hacen algunos, esa dialéctica de S. Agustín a una pura antítesis literaria equivaldría a tergiversar todo su pensamiento y a vaciarlo sin remedio de ese elemento dinámico y escatológico de la vida, de la Iglesia y de la historia, que mantiene la espe-

7. Cfr. A. Turrado, La antropología de S. Agustín, 75ss.; J. Pegueroles, San Agustín. Un platonismo cristiano, Barcelona 1985.

8. B. DE MARGERIE, Introduction à l'histoire de l'exégèse, 3 vol., Paris 1980-1983; M. SiMONETTI, Profilo storico dell'esegesi patristica, Roma 1981; J. DANIELOU, Sacramentos y culto según los SS. Padres, Madrid 1964, 23-25 (sobre Teodoro de Mopsuestia); R.A. GreER, Theodore of Mopsuestia Exegete and Theologian, London 1961; G. FERrARo, L'esposizione dei testi pneumatologici nel commento di Teodoro di Mopsuestia al Quarto Vangelo: Gregorianum 67 (1986) 265296. 
ranza en la utopía y el realismo de los contrastes y de las miserias humanas. Por eso Agustín sigue siendo, según el liberal A. von Harnack, «el primer hombre moderno» (den ersten modernen Menschen) ${ }^{9}$, y los participantes en el Vaticano II fueron en buena parte llevados por Agustín a redescubrir el carácter escatológico de la Iglesia y del hombre hecho a imagen de Dios ${ }^{10}$.

Pero esa mentalidad dialéctica y utópica tiene también sus problemas a la hora de aplicarla a la vida concreta. Como no pretendemos en modo alguno hacer apologética de S. Agustín, sino más bien tratar de comprenderlo mejor, no estará de más recordar de antemano la cuestión de la indisolubilidad del matrimonio cristiano, que en Agustín adquiere una gran dureza si se le compara con los Padres griegos, en especial con los célebres cánones de S. Basilio. Pues bien; creo que en ese caso la ignorancia del hebreo fue la causa de que Agustín no comprendiera que precisamente en los textos bíblicos que él cita, basados en la expresión inicial del Génesis: «y serán los dos una sola carne (lebasär)» (2,24), se trata de la utopía o ideal siguiente: e irán haciéndose por el amor una sola persona moral. Es un ideal que obliga a muchas cosas, y que S. Pablo no duda en comparar de algún modo con el amor de Cristo a su Iglesia (Ef 5,32-33). Con todo, bajo esa perspectiva ideal S. Pablo o el paulinismo describe más adelante el llamado privilegio paulino (1Cor 7), que aún conserva el Derecho Canónico, y S. Mateo (cc. 5 y 19) habla a los judío-cristianos de una excepción muy notable, probablemente de la «infidelidad» en el sentido bíblico de alejamiento de Dios (pornèia) como excepción que rompe la realidad de dicho ideal ${ }^{11}$; en ese caso, «de alejamiento mutuo entre los esposos» y de un modo definitivo. Esta breve mención debiera hacernos pensar en la responsabilidad tremenda que tenemos de volver a interpretar la Biblia desde su mentalidad semita y escatológica, y no desde unas categorías helénicas y totalmente extrañas a ella, que la desvirtúan y que traen como consecuencias a veces una abierta deshumanización del cristianismo.

$\mathrm{Y}$ esto mismo es lo que ha pasado con algunas cuestiones fundamentales de la doctrina de S. Agustín a través de los siglos precisamente por no tener en cuenta esa característica esencial de su personalidad, es decir, su mentah-

9. A. von Harnack, Das Wesen des Christentums, Leipzig 1908, 161.

10. Ver a este respecto al agustinólogo y autor del esquema inicial de la Const. sobre la Iglesia del Vat. II, G. Philips, La Iglesia y su misterio en el concilio Vaticano II. Historia, texto y comentario de la Constitución «Lumen Gentium», 2 vol., Barcelona 1969.

11. Cfr. A. TurRado, Reflexiones acerca del impropiamente llamado divorcio: Revista Agustiniana 21 (1980) 357-402; V.J. PoPOSHIL, Divorcio y nuevo matrimonio. Jalones para una doctrina católica nueva. Buenos Aires-México, 1969; W. KASPER, Zur Theologie der christlichen Ehe. Mainz 1977; J. GRUNDEL, Die Zukunft der christlichen Ehe. Erwartungen, Konflikte, Orientierungshilfen, München 1978; A. MAтAвOSCH, Divorcio e Iglesia, Madrid 1979; J. Alonso Diaz, El divorcio, hoy. Desde la Biblia y la teología, Madrid 1981, etc. 
dad bíblica y neoplatónica anclada siempre en la utopía y en la dialéctica vital, del todo opuestas a los esquemas aristotélicos y a su ética de una naturaleza ideal e inexistente.

\section{La utopía de la «vera libertas» y el diálogo de la gracia}

Aquí trataré únicamente de dar una visión panorámica de la cuestión, porque ya la he desarrollado ampliamente en una obra muy reciente ${ }^{12}$.

No es posible analizar aquí toda la complejidad de la polémica antipelagiana, ni hoy día tendría ya mucho interés la lucha en torno a ciertas cuestiones antropológicas como la del pecado original y sus consecuencias (la ignorancia y la concupiscencia), que debieran estar ya superadas y reinterpretadas en virtud de la nueva hermenéutica bíblica, del evolucionismo científico como hipótesis admitida prácticamente por todos y del personalismo de la cultura actual, frente a la mentalidad tribal clásica, que no puede admitir más pecados que los personales en sentido estricto.

En cambio, sí es sumamente interesante el aspecto de la polémica pelagiana en lo tocante a la libertad y a la gracia, porque a través de la historia posterior de la Iglesia ha sido muy mal interpretada; en parte, porque los pelagianos, de cuño aristotélico, no comprendían la utopía agustiniana de la «verdadera libertad» en sentido evangélico, y en parte porque la teología medieval y más tarde los jansenistas cayeron en el error de atribuir a Agustín las categorías de Aristóteles tanto en su antropología (psicología racional) como en el fisicismo o determinismo de la acción de Dios y de la gracia.

S. Agustín fue descubriendo cada vez con más claridad que, en el fondo de la lucha de los pelagianos contra el pecado original para reducirlo a un puro «mal ejemplo de Adán», se ocultaba de hecho un optimismo naturalista muy en la línea de la ética de Aristóteles que llegaba a destruir la gratuidad del amor de Dios a la humanidad, es decir, «la gracia de Dios mediante Jesucristo», según la expresión favorita del Santo. Toda la polémica con Pelagio y aún con más dureza la polémica con Julián de Eclana tiene como substrato la noción que éstos tenían de libertad como la posibilidad del hombre para elegir entre el bien o el mal; definición que heredaron de los estoicos a través de los escritos de Cicerón.

Los pelagianos aplican esa noción de libertad a las tres etapas en que ellos dividen la historia de salvación: la de la naturaleza sin más; la de la Ley de Moisés; y la de Jesucristo con su doctrina y su ejemplo. Son etapas que se van excluyendo $o$ abrogando sucesivamente unas a otras, y en todas ellas la salva-

12. Cfr. A. Turrado, La antropología de S. Agustín, 99ss. 
ción dependerá, según ellos, de los méritos futuros de cada cual presabidos por Dios desde toda la eternidad. Es decir: que esas gracias múltiples (la naturaleza, la Ley, la doctrina y el ejemplo de Cristo, ijunto con la amenaza de los castigos eternos!) y Dios, el dador de las mismas, dependen de la libre voluntad del hombre. Éste era el centro de la cuestión, según nos lo dice Agustín ya al final de sus días en el libro Del don de la perseverancia:

«Y ¿qué es lo que me obligó a defender con más amplitud y claridad los textos de las Escrituras en que se nos habla de la predestinación, sino los pelagianos, cuando dicen que la gracia de Dios se nos da conforme a nuestros méritos? Y ¿qué es esto más que una negación absoluta de la gracia?» ${ }^{13}$.

La trilogía de los pelagianos: posse, velle, esse (poder, querer, hacer realmente) se daba en las tres etapas por ellos admitidas, pero de tal modo que la posibilidad de elegir el bien o el mal era el único don de Dios en la creación, en la Ley, en la doctrina de Cristo, mientras que el querer hacer el bien y el hacerlo realmente era sólo obra de los hombres ${ }^{14}$. De este modo, les decía S. Agustín, siguiendo al Apóstol: «se vacía de sentido a la cruz de Cristo» (1Cor 1,17); porque si la gracia se da en virtud de los méritos propios, entonces esa gracia ya no es gracia (Rom 11,6), sino más bien una deuda que haría a Dios dependiente de la voluntad de los hombres ${ }^{15}$. Por eso, Agustín, que bien podría ser llamado el Doctor del «Padrenuestro» en contra de los pelagianos, les repetirá sin cesar que con su naturalismo destruyen la oración que Jesús enseñó a los apóstoles y en ellos a toda la Iglesia, la cual, por toda la tierra, suplica sin cesar: ¡perdónanos nuestras deudas y no nos dejes caer en tentación!

Y es en este contexto de oración y de humildad en el que Agustín sitúa la utopía evangélica de la «verdadera libertad» cristiana, poniendo como ejemplar supremo de la misma al Padre celestial: Sed perfectos como lo es vuestro Padre celestial (Mt 5,48), el cual no puede pecar y vive felicísimamente. Así que la verdadera libertad no está en poder elegir entre el bien y el mal, sino en irse acercando más y más al liberarse de la misma posibilidad de pecar, a la feliz necesidad (beata necessitas) de hacer con gusto el bien ${ }^{16}$. Por eso Agustín trata por todos los medios de demostrar a los pelagianos, en especial a Julián de Eclana, que a veces lo que es necesario, lo que logra infaliblemente su fin, como la gracia de Dios por Cristo, que es deleite, atracción y caridad del Espí-

13. De dono persev. 20, 53 .

14. De nat. et gr. 6, 6; 7, 7-8; 9, 10 (textos que Agustín cita de las obras de Pelagio De natura y De libero arbitrio); De pecc. mer. et rem. 18-19, 29-32; De spir. et litt. 2, 4; De gr. Christi et de pecc. orig. I, 3, 3; 3, 4-5; 4, 5-6; De gestis Pel. 6, 6-20; 8, 21; 10, 22, etc.

15. De nat. et gr. 6, 6; 7, 7-8; De gestis Pel. 14, 32-37; 17, 40-41; Op. imperf. c. Jul. I, 94.

16. «Si liberum non est, nisi quod duo potest velle, id est, et bonum et malum: liber Deus non est, qui malum non potest velle» (Op. imperf. c. Jul. I, 100); Ib. V; 53. 
ritu Santo, es también voluntario, lo más voluntario y más conforme con el libre albedrío, del mismo modo que el deseo de la felicidad es innato o necesario en todos los humanos, y sin embargo es lo más voluntario ${ }^{17}$. Ésa es la verdadera libertad humana, de la que ya gozan también los bienaventurados por la gracia de Dios.

Esa utopía de la «verdadera libertad» no la podían comprender los pelagianos, los cuales, a pesar de su optimismo naturalista, caían en un puritanismo contradictorio y en una ascesis extraña a la mentalidad evangélica, puesto que el ideal o la utopía del cristianismo consiste precisamente, no en estar agobiados por el temor de los castigos eternos, sino en vivir de tal modo que «el amor vaya expulsando de nuestro corazón ese temor» (1Jn 4,18) ${ }^{18}$.

Esta mentalidad de Agustín, que aquí ofrecemos únicamente en una visión muy general, no fue tampoco comprendida ya por los principales autores de la escolástica, incluido santo Tomás, precisamente porque su definición de la libertad era la misma que la de los pelagianos y porque el aristotelismo cierra el paso a toda posible utopía que sobrepase los límites de la «racionalidad». Agustín tiene una noción dinámica y unitaria del hombre, y ese dinamismo se concretiza en una actividad radical y conjunta de «amarse, conocerse y recordarse» (la autoconciencia como contacto inmediato consigo mismo); mientras que la psicología racional del aristotelismo defiende las tres potencias del alma (memoria, inteligencia y voluntad) como realmente distintas entre sí y realmente distintas del alma. De este modo, la actividad humana se disocia y se contrapone sin cesar, y los dualismos de todo tipo se suceden en todos los campos de la vida: natural-sobrenatural, gracias actuales-gracia habitual, materias y formas, etc. Por eso Bayo y Jansenio y sus seguidores a partir de finales del siglo XVI, enfrascados ya en ese contexto aristotélico tomista, no pudieron comprender a S. Agustín y destruyeron totalmente su doctrina más preciosa: la gracia como un diálogo. Ese deseo innato de la felicidad, situado por ellos en la ontología estática griega, y no en la dinámica e histórica de la Biblia y de Agustín, resultaba una exigencia ontológica y jurídica de la gracia de Dios como medio necesario para poder lograr esa felicidad o visión beatífica cuyo deseo fue impreso en nuestra alma por el Creador. No puede darse una corrupción mayor de la doctrina de S. Agustín sobre la gracia y la oración humilde y confiada en el Mediador, Jesucristo ${ }^{19}$.

17. Op. imperf. c. Jul. I, 100; 101-102; 47; 76; 81; 84; 93; 97-98; 103-105; II, 105; 107-108; 165; III, 110-112; 122; V, 38-44; 50-54; 60-64; VI, 5; 8-13; 17; De civ. Dei XXII, 30, 3, etc.

18. De spir. et litt. 3,$5 ; 16,25,42 ; 29,51$; De pecc. mer. et rem. II, 17, 26; 19, 32-33; De nat. et gr. 57, 67; 69-70, 83-84; Contra duas Ep. Pel. I, 3, 7; II, 8-9, 17-21; De gr. Christi et de pecc. orig. I, 8-14, 9-15; 45-46, 49-51; Contra Jul. I, 14, 66-74; V, 4, 15, etc.

19. Cfr. A. Turrado, La antropología de S. Agustín, 125ss.; H. De LuBAC, Augustinisme 
Si prescindimos de la doctrina mítica del pecado de Adán y Eva y, según lo hemos indicado antes, del consiguiente pecado de origen como causa de la situación de lucha y de pecado de la humanidad (género etiológico), nadie como Agustín describe de hecho los contrastes y las miserias de los hombres, ni nadie como él, siguiendo al Apóstol, canta con tanta unción y entusiasmo las maravillas del único Mediador entre Dios y los hombres.

Hoy día, después que el Vaticano II ha vuelto a construir la historia de salvación partiendo de la teología de la creación y, por lo tanto, de la «rectitud de conciencia como criterio último de moral y, por lo mismo, de salvación» (Const. Gaudium et Spes, nn. 12-17,22) ${ }^{20}$, es preciso superar de hecho las limitaciones de la doctrina tradicional de la «Iglesia como arca única de salvación», y situar la doctrina agustiniana de la gracia en el ámbito consciente de la vida cristiana.

De todos modos el diálogo de gracia entre Dios y los hombres mediante Jesucristo y mediante su sacramento, la Iglesia, no ha sido captado en toda su profundidad por los estudios numerosos que se le han dedicado ${ }^{21}$. Es preciso situarlo en la perspectiva de Cristo «Sacramento del amor de Dios y único ejemplo para nosotros», según veremos. Pero, según Agustín repetía a los pelagianos, no debemos limitarnos a considerar el aspecto de ejemplaridad de la vida de Cristo, sino que es preciso atender ante todo a su acción interna en nuestra alma (intus, intrinsecus) ${ }^{22}$, a ese don interior que él llama de continuo delectación, atracción, fuerza, suavidad y sobre todo caridad del Espíritu Santo derramada en nuestros corazones $(\mathrm{Rm} 5,5)$, para cumplir con agrado la voluntad de Dios ${ }^{23}$. Y en ese diálogo, esencialmente trinitario, no se da violencia alguna de Dios al hombre, puesto que el deleite y la caridad llevan consigo la libertad del amor: "In recte faciendo ideo nullum est vinculum necessitatis, quia libertas est caritatis» ${ }^{24}$. En nuestra terminología moderna diríamos que

et théologie moderne, Paris 1965; Id., Le mystère du surnaturel, Paris 1965; L. CEYSSENS, Sources relatives aux débuts du Jansénisme et de l'antijansénisme, 1640-1643, Louvain 1957; M. RocA, Génesis histórica de la bula «Ex omnibus afflictionibus», Madrid 1956; V. GRossi, Baio e Bellarmino interpreti di S. Agostino nelle questioni del soprannaturale, Roma 1968.

20. Cfr. A. Turrado, Iglesia-Ideologías-Salvación. Cuerpo de Cristo y salvación en la doctrina de S. Agustín y del Vaticano II: Estudios Eclesiásticos 48 (1973) 327-358; C. MAYER, Zum Wandel des schöpfungstheologischen Denkens in der katholischen Dogmatik: Theologische Quartalschrift 158 (1978) 233ss.

21. Cfr. H. RonDET, La gracia de Cristo, Barcelona 1966; M. HuFTIER, Libre arbitre, liberté et péché chez saint Augustin, Louvain 1966; J.P. BuRins, The Devolopment of Augustine's Doctrine of Operative Grace, Paris 1980.

22. Cfr. A. TurRado, Dios en el hombre, BAC, Madrid 1971, 153ss.

23. De spir. et litt. 16, 45; De nat. et gr. 1-2; De gr. et lib. arb. 13, 25; Op. imperf. c. Jul. I, 94-95; II, 146, 165; V, 48; De gestis Pel. 31, 56; 35, 61.

24. De nat. et gr. 65, 78; «lex libertatis, lex caritatis» (Ep. 167, 6, 19). 
el deseo del placer (voluptas), en este caso del placer del bien que da sentido a toda nuestra vida, dirige todas las motivaciones y las actitudes hacia el seguimiento de Cristo por amor, que es lo más íntimo y profundo de nuestro ser. Él mismo lo afirma así en sus comentarios al evangelio de S. Juan, al recordar la frase de Virgilio de que «el deseo del placer todo lo mueve» (trahit sua quemque voluptas: Égloga 2): Jesús es el pan del cielo, y hay un cierto deseo de placer del corazón para el que es dulce ese pan celestial; no arrastra la necesidad, sino el deseo del placer; no la obligación, sino la deleitación: ¿cuánto más entonces deberemos decir que es atraído hacia Cristo el hombre que se deleita en la verdad, en la felicidad, en la justicia, en la vida eterna, todo lo cual es Cristo? ${ }^{25}$.

Dios lleva siempre la iniciativa en ese diálogo de gracia, pero la respuesta es también del hombre, y por lo mismo es un diálogo en el que actúan Dios y el hombre. Somos realmente libres, porque aceptamos libremente esta atracción de amor interior hacia el bien: ibi sumus veraciter liberi, ubi non delectamur ${ }_{\text {inviti }}{ }^{26}$. Ése es el sentido profundo y del todo acorde con la psicología moderna sobre el elemento volitivo como fuerza motriz de la vida, y de ese modo se ha de interpretar la célebre "deleitación vencedora» (delectatio victrix) de Agustín ${ }^{27}$, tan adulterada por los jansenistas y por otros autores modernos al contemplarla como una negación de la libertad humana. De nuevo vemos cómo no se le puede entender sin la perspectiva utópica y evangélica de la «verdadera libertad» como la esperanza de llegar algún día a la posibilidad de no poder pecar y de seguir por gracia al Padre celestial, que ama a todos los hombres, justos y pecadores.

Ahora «Dios hace que hagamos», nos dirá Agustín sin cesar: ille facit ut velimus, ille facit ut faciamus, en ese sentido de ayuda deleitosa o motivación de amor para cumplir su voluntad ${ }^{28}$. Dios hace que los suyos hagan el bien libremente y por amor: Sed suos id volentes facit ${ }^{29}$.

La dialéctica vital de la Biblia aparece en todo este panorama como una lucha interior que causa debilidad y atrae hacia el pecado, según lo hemos mencionado ya repetidas veces, de ahí que sea necesaria la oración y la viven-

25. In Io. tr. 26, 4; «quod enim amplius delectat, secundum id operemur necesse est» (Expos. ad Gal. 49); «secundum enim hoc vivit quisque quod diligit» (De Trin. XIII, 20, 26).

26. De nupt. et concup. I, 30,33.

27. De pecc. mer. et rem. II, 19, 32 . 17-21.

28. De gr. et lib. arb. 16-17, 32-33; De corrept. et gr. 2, 3-4; Contra duas ep. Pel. II, 8-9,

29. De civ. Dei, XXI, 2, 1. Por eso no creo objetiva la interpretación que hace G. Greshake, Geschenkte Freiheit. Einführung in die Gnadenlehre (Freiburg-Basel-Wien 1977) al atribuir a Agustín el dilema: Dios o el hombre, mientras que trata de reivindicar al Pelagio con el esquema integrador: Dios y el hombre. 
cia profunda de nuestra filiación divina unidos al Mediador para que la voluntad sea robustecida de continuo y no se oponga a la voluntad de Dios por el pecado, que es lo único exclusivamente nuestro.

Veamos, pues, brevemente, cómo concibe S. Agustín esa mediación de Cristo en cuanto sacramento del amor de Dios y ejemplo supremo de ese amor.

3. La utopía de Cristo «Sacramento del amor de Dios y nuestro único ejemplo» y el sentido escatológico de nuestra perfección y de la vida de la Iglesia

No es mi propósito hacer aquí un análisis de la cristología de S. Agustín, realizado ya por varios autores modernos ${ }^{30}$, si bien algunos parece que no pueden comprender fácilmente los tres modos como Agustín entiende o contempla a Jesucristo: como divinidad eterna e igual al Padre; como Dios y hombre después de la encarnación; y como el Cristo total (totus Christus) en la plenitud de la Iglesia, como cabeza y cuerpo al modo de un cierto varón perfecto del que todos somos miembros ${ }^{31}$. Es cierto que a veces aparece en todos los santos Padres griegos y latinos el dualismo antropológico griego (cuerpoalma) al exponer la metáfora paulina del «cuerpo de Cristo» de tal modo que el cuerpo serían la cabeza, Cristo, y los fieles, sus miembros, atribuyendo al Espíritu Santo la función del alma vivificadora; en esto se apartan obviamente del sentido de cuerpo (basār) como «persona visible» de la mentalidad hebrea del Apóstol. Sin embargo, a la hora de expresar el contenido real y dinámico de esa metáfora, Agustín se cuida atentamente de relacionar la función mediadora de Cristo-Cabeza y la caridad como elemento que une y hace crecer a los miembros del Cuerpo y que «es difundida en nuestros corazones por el Espíritu Santo que nos ha sido dado» (Rom 5, 5). Es éste un punto de vista esencial en la doctrina de S. Agustín, íntimamente unido a la contemplación de la Iglesia como un templo de Dios, formado de piedras vivas cuya juntura es la caridad, así como la vivencia de la Eucaristía como sacramento y vínculo de la unidad del Cuerpo de Cristo ${ }^{32}$.

30. T.J. VAN BAVEL, Recherches sur la christologie de saint Augustin, Fribourg 1954; T.J. van Bavel-B. Brunig, Die Einheit des «Totus Christus» bei Augustin, en «C.P. MayerW. Eckermann (Hrsg.), Scientia Augustiniana. Studien über Augustinus, den Augustinismus und den Augustinerorden, Festschrift A. Zumkeller, Würzburg 1975, 43-75. Resumen del tema en A. Grillmeier, Jesus der Christus im Glauben der Kirche. Bd. I, Von der Apostolischen Zeit bis zum Konzil von Chalcedon (451), Freiburg-Basel-Wien 1982, 594-604.

31. S. 341,1 .

32. Cfr. A. Turrado, Dios y el hombre, 231-253; J. RATZINGER, Volk und Haus Gottes in Augustins Lehre von der Kirche, München 1954; S.J. GRABOWSKI, La Iglesia. Introducción a la teología de San Agustín, Madrid 1965; Y. CONGAR, L'Église de saint Augustin à l'époque moderne, Paris 1970. 
Y creo que en torno a la caridad se mueve la doctrina de Agustín acerca de la sacramentalidad de Cristo y de la Iglesia. Algunos autores modernos se enfrascan en discusiones sin fin sobre el sentido preciso de los términos «sacramento y ejemplo» atribuidos por Agustín a Cristo, como si en él esos términos tuvieran siempre el mismo significado, en vez de atender al contexto en que los usa. Analizando esa misma expresión en S. León Magno, en que el término sacramento se refiere a Cristo en cuanto fuente de la gracia, mientras que Cristo como ejemplo sería para expresar su función de modelo de la vida o ética cristiana ${ }^{33}$, algunos encuentran en Agustín esa misma antítesis sin más, afirmando que sin duda S. León la heredó de Agustín como tantas otras formulaciones de la cristología latina.

Sin embargo, creo que Agustín se mueve aquí en la dialéctica de la utopía evangélica del amor supremo de Dios manifestado en Cristo, el Mediador, (Cristo-Sacramento) y el seguimiento de Cristo en ese amor por parte nuestra, que en esta vida no podrá ser más que eso, un seguimiento en pos del ejemplar supremo y visible para nosotros: para ser nosotros también sacramentos de Cristo y para conocer su caridad sin límites, tenemos que amar con todas nuestras fuerzas: pero ¿acaso nos vamos a hacer la ilusión de que podremos amar como él amó? (sed numquid amatis quantum ille amavit?) ${ }^{34}$. En su obra De Trinitate, en la que Agustín llama a Cristo varias veces sacramento en el contexto de su ser y de sus funciones: Hoc sacramentum, hoc sacrificium, hic sacerdos, hic Deus, antequam missus veniret... para devolver a la unidad, a los que estábamos en la desemejanza y en la variedad de las cosas por nuestra iniquidad, haciendo de muchos un solo cuerpo y rogando al Padre para que todos sean uno ${ }^{35}$, no deja de contemplar esa sacramentalidad de Cristo, a partir de su encarnación, como ejemplo supremo de humildad, como medicina suprema de nuestra soberbia y como sacramento del amor de Dios hacia nosotros por el cual se disuelven los lazos del pecado: ad humilitatis exemplum, ad demonstrandam erga nos dilectionem Dei... summum medicamentum quo superbiae nostrae sanaretur tumor, et altum sacramentum quo peccati vinculum solveretur ${ }^{36}$.

No se trata, pues, simplemente de una antítesis entre Cristo-Sacramento en cuanto fuente de la gracia y Cristo-Ejemplo en cuanto modelo de la ética cristiana. Es más bien una relación integradora entre Cristo, ejemplo supremo

33. Cfr. B. StUder, «Sacramentum et exemplum» chez saint Augustin, en «Recherches Augustiniennes», X, (Paris 1975) 87-141; W. GeERLINGS, Christus exemplum. Studien zur Christologie und Christusverkündigung Augustins, Mainz 1978.

34. In Ps. 103, s. 1, 14.

35. De Trin. IV, 7, 11; 12, 15.

36. De Trin. VIII, 5,7 . 
del amor social (al Padre y a los hombres) hasta la muerte de cruz, precisamente por encarnar en sí ese amor o caridad haciendo visible y comunicando el amor del Padre mediante el Espíritu Santo de ambos que nos ha sido dado $(\operatorname{Rm} 5,5)$. La dialéctica vital, que hace trabajoso nuestro seguimiento de Cristo en ese amor, es la lucha interior y exterior entre el bien y el mal, entre el hombre nuevo y el hombre viejo, entre el ansia de las cosas temporales y la libertad del amor (libertas caritatis) que va expulsando el temor (1Jn 4, 18); y en esa lucha, Cristo es el ejemplo supremo y único: Hic praestantissimum illud et unicum exemplum Dominici hominis proponendum est ${ }^{37}$.

Sería imposible recoger aquí la inmensidad de textos que Agustín dedica a esta visión tan sublime como práctica de Jesucristo, el Mediador y Médico humilde de nuestras llagas y miserias, algunos de los cuales son impresionantes: al tomar la forma de esclavo (Flp 2, 7), vino a nosotros a este mundo (1Tm 1, 15), el que ya estaba en este mundo, porque el mundo fue creado mediante él (Jn 1, 10): «ejemplo arriba para los que ven a Dios, ejemplo abajo para los que le admiran como hombre, ejemplo para los sanos a perseverar, ejemplo para los enfermos a convalecer, ejemplo para los moribundos a no temer, ejemplo para los muertos a resucitar, teniendo él mismo la primacía en todo $(\mathrm{Col} 1,18)$. Y puesto que el hombre, para su felicidad, no podía buscar sino a Dios, y a Dios no lo podía sentir, siguiendo al Dios hecho hombre podría ya seguir al mismo tiempo al que puede sentir y al que debe seguir. Amémosle, pues, y unámonos a él con la caridad difundida en nuestros corazones por el Espíritu Santo que nos ha sido dado ( $\mathrm{Rm} 5,5)$. No es, pues, extraño que, debido al ejemplo que nos da la imagen igual al Padre para que nos reformemos a imagen de Dios, cuando la Escritura habla de la sabiduría, esté hablando del Hijo, al cual seguimos viviendo con sabiduría» ${ }^{38}$.

El seguimiento de Cristo es una utopía que mueve nuestros pasos e ilumina nuestro camino, porque sólo él es el salvador que da su vida por el perdón de los pecados, y sólo él no tuvo pecado, sino que se hizo pecado o víctima del pecado por nosotros. Así que, más que imitarle, deberíamos congratularnos por lo que él hizo por nosotros, y seguirle llenos de humildad y de obediencia piadosa: Eumque sic imitemur pia obedientia, et ei nos comparare nulla praesumamus audacia ${ }^{39}$. Y sin embargo, aunque Cristo no tuviera la concupiscencia, según pretendían atribuírsela los pelagianos para insistir en Cristo como ejemplo del hombre para regularla, Agustín les dirá con insistencia que Cristo sigue siendo nuestro ejemplo supremo del mismo modo que lo es el Padre ce-

37. De div. quaest. 83, q. 36,2 .

38. De Trin. V, 3, 5 .

39. In Io. tr. 84,2 . 
lestial (Mt 5, 48) a quien nunca lograremos imitar plenamente ${ }^{40}$. Esto es captar el sentido profundo y animador que debe tener en nuestra vida cristiana la utopía o el ejemplo supremo de toda perfección para no dormirnos en nuestros laureles.

«Todos somos imperfectos» (Omnes enim imperfecti sumus). Pero el Evangelio es el ejemplo que Cristo nos dejó en la tierra hasta la consumación de los siglos. Él está contigo en el Evangelio (in Evangelio tecum est), para que lo sigas, y seguirlo es imitarlo, es aprender de él a ser manso y humilde de corazón. Si bien sin la caridad nada me puede aprovechar (1Cor 13, 1-3). «Por eso os exhorto a perfeccionar la caridad, y os ruego que pidáis por mí para que vaya perfeccionando en mí lo que os exhorto a vosotros. Pues todos somos imperfectos y sólo alcanzaremos la perfección allí en donde todas las cosas son perfectas. Así nos lo dice el Apóstol (Flp 3, 12-13). Y iquién de los hombres osará jactarse de la perfección? Antes bien, confesemos nuestras imperfecciones a fin de que merezcamos la perfección»" ${ }^{41}$.

Me referiré ahora muy brevemente a la utopía de la Iglesia «santa e inmaculada» en esperanza, en la que durante este período terrenal están juntos el grano y la paja hasta que llegue la criba definitiva del juicio final. Es el tema constante en los escritos. de Agustín contra el «puritanismo» doloso de los donatistas, que se repetirá con nuevo vigor contra los pelagianos. Toda la Iglesia repite de continuo la oración del Señor: Perdónanos nuestras deudas y no nos dejes caer en tentación ${ }^{42}$. Por eso hay que ser realistas y humildes, y admitir que la Iglesia sin mancha ni arruga de que habla S. Pablo (Ef 5, 27) es sin duda la Iglesia ya gloriosa en la vida eterna: «Y ciertamente no podemos decir que sea ya gloriosa en la actualidad en medio de tantos males, de tantos escándalos, con esa mezcla tremenda de hombres pésimos y con el oprobio de tantos impíos y mucho menos podemos decir eso porque la sirvan los reyes, porque ésta sí que es la tentación más grande y más peligrosa» ${ }^{43}$.

Su noción dinámica y escatológica de la Iglesia hace que la contemple como sacramento de Cristo, es decir, como su cuerpo visible que lo manifiesta y lo comunica a los demás; que nació del costado abierto de Cristo en la cruz, del que fluyeron agua y sangre, es decir, de la fe de la pasión y del bautismo, y cuya fortaleza o perennidad, a semejanza de la dureza del hueso o costilla de Adán para formar a Eva, le viene precisamente de la debilidad de Cristo muerto en la cruz, como Adán que había sido creado del débil barro. Pero, como

40. Op. imperf. c. Jul. IV, 87, 89; VI, 34.

41. S. 142, 9, 10; S. 96, 3ss.; S. 304, 2ss.; In Ps. 49, 4; In Ps. 39, 25; De civ. Dei XIX, 27.

42. S. 181, 2-5; De pecc. mer. et rem. II, 16, 24; De nat. et gr. 36, 42 (donde considera sólo a María libre de todo pecado o falta de caridad); De dono persev. 5,8 , etc.

43. De perfect. just. hom. 15,35 . 
dice S. Pablo con su dialéctica soteriológica, la debilidad de Cristo en la cruz es nuestra fortaleza: «Christus est et Ecclesia, illius infirmitas nostra est fortitudo» ${ }^{44}$.

Para Agustín es únicamente Cristo el «Sacramento del amor de Dios y el ejemplo supremo del amor social», que es a su vez el camino para nuestra respuesta al amor de Dios, buscando como Cristo, no los propios intereses, sino el bien de los demás ${ }^{45}$. Bajo esta perspectiva, Cristo es el ejemplo supremo para todos los cristianos, y de un modo especial para los que le sigan en la vida de los consejos evangélicos y para los ministros o servidores (servus = $i$ esclavo en el derecho romano!) de los demás en la palabra, en los sacramentos y en toda su vida ${ }^{45}$.

A este respecto, sólo quisiera recordar aquí que la noción que Agustín, siguiendo a Orígenes, tiene de la función de Pedro en la Iglesia debiera ser tenida muy en cuenta, a pesar de que algunos la vean como una de las causas de la postura de Lutero frente al papa. Al comentar el texto de Mt 16, 15ss.: «Tú eres Pedro, y sobre esta piedra edificaré mi Iglesia...», Agustín afirma siempre que la verdadera piedra sobre la que Cristo edificará su Iglesia es el mismo Cristo o la fe en Cristo que tiene Pedro como símbolo de toda la Iglesia ${ }^{46}$. Alguno se sorprenderá tal vez al leer en Agustín frases como ésta: nosotros somos cristianos, no petrianos (Sumus enim Christiani, non Petriani) ${ }^{47}$; o cuando dice que Cristo es quien gobierna a la Iglesia desde el árbol de la cruz ${ }^{48}$. Sin embargo, para Agustín, que tiene una concepción de la Iglesia como «comunión» de los creyentes o "como una persona mística», compuesta de CristoCabeza, y de los fieles como miembros de ese cuerpo, todos los ministerios reciben su sentido precisamente por ser útiles en y para la Iglesia, y por ser, a ejemplo de Cristo, un servicio o esclavitud, una entrega de amor hasta el sacrificio de la propia vida por servir a las «ovejas de la grey de Cristo» ${ }^{49}$. Todo se mueve, pues, en una utopía y en una dialéctica de Pedro (y los demás apóstoles con él) como piedra visible al servicio de la fe en Cristo, y Cristo mismo co-

44. In Io. tr. 15, 8; De Gen. c. Manich. II, 24, 37; In Ps. 40, 10; In Ps. 56, 11; In Ps. 126, 7; In Ps. 138, 2; S. 218, 14; De civ. Dei XV, 26, 1; «inde Sacramenta manarunt, quibus credentes initiantur». Si bien para Agustín el término sácramento tiene el sentido amplio de «signos que dicen relación a las cosas divinas que Dios nos da para la perfección y la salvación» $(E p .138,1,6)$.

45. Cfr. L. VerheIJEN, Élements d'un commentaire de la Règle de saint Augustin, XX. La charité ne cherche pas ses propres intérêts: Augustiniana 34 (1984) 75-144; ver p. 90ss.

46. In Ps. 103 en sus 4 sermones: s. 1, 17; s. 2, 5; s. 3, 5-7 (piedras Pedro y Pablo por su fe en Cristo); s. 4, 4; Contra litt. Petil. II, 108, 247 (la fe y la confianza en Cristo, no en Pedro o en Pablo).

47. In Ps. 44, 23.

48. In Ps. 103, s. 4, 4.

49. S. 46 (todo); S. $47,8-9$; S. $137,3-5$; S. 128 , 7; S. 138 , 4ss.; SS. 295-299. 
mo piedra invisible que sustenta la fe de Pedro y de toda la Iglesia. Es obvio que, en su noción dinámica y escatológica de la Iglesia, nadie puede representar a Cristo plenamente o con toda perfección; esto es una utopía que debe servir de acicate perenne a sus ministros y en especial a los sucesores de Pedro para tratar de ser sus representantes lo más digna y fielmente posible, actuando siempre movidos por la caridad o el amor que Cristo pidió con tanta insistencia a Pedro antes de encomendarle el cuidado de su grey: «Se le pedía el amor, y se lo imponía la labor, porque donde mayor sea el amor, menor será la labor» ${ }^{50}$.

La «Constitución dogmática sobre la Iglesia» del Vaticano II, nos enseña, citando al Vaticano I, que Cristo instituyó en la persona de Pedro «el principio y fundamento, perpetuo y visible, de la unidad de fe y.de comunión» (n. 18), y creo que ese aspecto de los ministerios al servicio de la fe y la comunión, con el ejemplo y el mandato de Jesús de ser «diáconos y esclavos» (ser$v i=$ doúloi) de los demás, debería ser la médula de las normas canónicas que regulan la vida social de la Iglesia, desacralizando todo aquello que hay de $j u$ ridicismo tomado del derecho romano y que, en vez de servir al fomento de la fe cristiana, es un estorbo y una falta muy grave contra el Evangelio. En medio de tantas discusiones como sigue habiendo sobre los primados y su alcance, con un dualismo tremendo entre ministerios y «el resto» de la Iglesia ${ }^{51}$, mejor sería volver con Agustín a la integración armoniosa entre los carismas institucionales y el Evangelio, abandonando en buena parte la línea de S. León Magno y de las Pseudo-Decretales Isidorianas.

De nuevo la utopía evangélica del seguimiento y de la representación de Cristo en la tierra pierde en gran parte su sentido precisamente porque su institucionalización tiende a romper la dialéctica vital entre una utopía anhelada y nunca plenamente alcanzada en esta vida y las miserias reales de las formas concretas con que los hombres y las mujeres de la Iglesia, influidos por las culturas, la han ido plasmando a través de los siglos.

$\mathrm{Y}$ esto nos lleva a recordar brevemente uno de los casos más graves de adulteración de la doctrina de S. Agustín, es decir, su utopía política de la única justicia verdadera.

50. «Interrogabatur amor, et imponebatur labor: quia ubi maior est amor, minor est labor» (S. 340, 1); S. 46, 11, 23; S. 137, 3-4; S. 253; S. 285, 5-6; In Ps. 36, s. 2, 8; In Ep. Io. ad Parthos tr. 5, 5, etc. Cfr. D. Lourt, Le reniement et l'amour de Pierre dans la prédication de saint Augustin, en «Recherches Augustiniennes», X, Paris 1975, 217-268; L. VERHEIJEN, art. c. en la n. 45 , p. 119ss.

51. Cfr. J.A. EstradA, La Iglesia: ¿Institución o carisma?, Salamanca 1984, 221ss.; Id., La Iglesia: Identidad y cambio. El concepto de la Iglesia del Vaticano I a nuestros días, Madrid 1985; Charisma und Institution, hrsg. von T. Rendtorff, Gütersloh 1985. 
4. La utopía de la «única verdadera justicia y verdadera república» y el sentido escatológico de todos los modelos de sociedad

Como no podía ser menos, el tema político, en el que se juega la ambición del poder, ha sido uno de los más tormentosos en la historia de la interpretación de Agustín.

La llamada «Iglesia de cristiandad» de la Edad Media fue el culmen de la adulteración de la utopía agustiniana de la «verdadera justicia» como condición necesaria para una «verdadera república» en contra de Cicerón. Algunos autores modernos, como H.X. Arquillière, É. Gilson, P. Mandonnet, llaman agustinismo político a la interpretación del Estado en la Iglesia o, como dice É. Gilson, a la absorción del derecho natural del Estado en la justicia sobrenatural y en el derecho eclesiástico ${ }^{52}$. En cambio, H. De Lubac opina que este mal llamado «agustinismo político» es un mito nacido de un sinfín de prejuicios, de confusiones del lenguaje y de contradicciones, incluso cuando tratan de enfrentar el agustinismo y el aristotelismo en dos bloques rivales en la historia política de la Iglesia de occidente ${ }^{53}$.

Aquí me limitaré a hacer un breve resumen de la génesis de esa «Iglesia de cristiandad», tomándolo de otro estudio anterior ${ }^{54}$, para hacer después unas reflexiones sobre la muerte de la utopía y sus consecuencias.

Pues bien; esa identificación de la Iglesia con la ciudad de Dios y del Imperio romano con la ciudad terrena se inició muy pronto en la historia de la Iglesia y va cambiando de panorama hasta desembocar en la sociedad teocrática medieval.

Ya aparece esa idea en la dotrina de Gelasio I (492-496) por su viva con-

52. Ver una amplia y profunda exposición de este tema en F.M. Tomás Ramos, $A$ idéia de Estado na doutrina ético-política de S. Agostinho. Um estudo do epistolário comparado com o «De Civitate Dei», São Paulo 1984; sobre el agustinismo político, p. 266ss.

53. H. De LuBAC, Augustinisme politique? Théologies d'occasion, Paris 1984 (24 estudios anteriores reelaborados).

54. M.-D. CHENU, Dogme et théologie dans la Bulle «Unam Sanctam»: Recherches de science religieuse 40 (1952) 307-312 (Mélanges Lebreton); Id., El Evangelio en el tiempo, Barcelona 1966; Y. CongAR, La demasiado famosa teoría de las dos espadas, en «Santa Iglesia», Barcelona $1965,362 s s$. La utopía metafísica y la utopía política de la «República» de Platón, mezcladas así de un modo híbrido con el cristianismo, perdían toda su fuerza dialéctica y motriz de la historia al ser llevadas a la realidad en un contexto de poderes absolutos (monarquías, papado). Con esto triunfaba de hecho la doctrina de la «Política» de Aristóteles y su carácter tan pragmático como esencialista: da muerte a la utopía platónica al ensalzar los éxitos de la polis o ciudad, y al fundar la existencia de ésta en la naturaleza social del hombre (animal político, zoon politikón), proponiéndola como anterior por naturaleza a la familia y al individuo mismo; con tanta «racionalidad» se legitimaba el status político reinante, la persona queda absorbida por la institución, y tendrán que pasar varios siglos hasta que las nuevas utopías sociopolíticas quebranten el orden social y económico cargado de desigualdad y de un falso providencialismo estoico. 
ciencia de que él tiene que dar también cuenta al Juez Supremo de la conducta de los reyes. Por otra parte, Carlomagno, cuyo libro preferido era La Ciudad de Dios, se inclinará a identificar su imperio con la ciudad de Dios y a los pueblos paganos con la ciudad terrena. Las mutuas interferencias y destituciones de los emperadores del Sacro Imperio romano-germánico y de los papas durante los siglos IX y X irán a desembocar en la idea del poder absoluto del papado a partir de León IX (1048), según la doctrina elaborada por el cardenal Humberto, que hará de la Iglesia de Roma el compendio de toda la Iglesia. Siguen fomentando esta idea los papas Nicolás II, Alejandro II, Gregorio VII (1073-1085) con su célebre reforma gregoriana; y aún más Inocencio III (+ 1216), llegando a alcanzar su culmen en la bula Unam Sanctam de Bonifacio VIII (a. 1301), con la teoría de las dos espadas o dos banderas, que atribuía al papa la suprema potestad directiva de la Iglesia y del Imperio. Se llega así a la cúspide de la sociedad teocrática medieval, en la que se entremezclan la situación especial de la Iglesia de occidente y una especie de metafísica social, de tipo platónico, bajo el influjo de las ideas del Pseudo-Dionisio sobre el ideal de la jerarquía única por la reducción de lo múltiple e imperfecto a la unidad. De este modo el papa, y sólo él, sería con todo derecho la encarnación viviente de la Unidad.

En ese ambiente comenzaron a aparecer los primeros tratados de eclesiología, que son más bien un reflejo de la filosofía neoplatónica y del derecho canónico en la línea pseudo-dionisiana antes mencionada ${ }^{55}$. La lucha del rey de Francia, Felipe el Hermoso (1285-1314), contra esas pretensiones papales, y las doctrinas de Guillermo de Ockham (+ 1349) serán el fermento que conducirá hacia los Estados soberanos e independientes de la Iglesia y al laicismo o secularización total de la mayor parte de las naciones modernas.

«La Ciudad de Dios» es ciertamente una teología de la historia en ese sentido dinámico y escatológico típico de S. Agustín, siguiendo a la Biblia, de tal modo que sus expresiones «Iglesia, ciudad de Dios, Reino de Dios, Reino de los cielos, lugar de paz y de justicia» son aspectos de una misma realidad utópica y siempre anhelada, que expresa las esperanzas de los hombres y las promesas de Cristo. Por eso el sentido de las mismas sólo puede captarse por el contexto ${ }^{56}$. Una vez más, la razón y la fe, las esperanzas humanas y las pro-

55. Santiago de Viterbo, De regimine christiano ad Clementem V, LL. 4, edic. Arquillière, Paris 1926; Egidio Romano, De ecclesiastica potestate, III, c. 2; Agustin Triunfo, Summa de potestate ecclesiastica. Cfr. U. MARIANI, Chiesa e Stato nei teologie agostiniani del secolo XIV, Roma 1957; Matteo Noveli e l'agostinismo politico del Trecento, Rocca-Palermo 1983 (art. de A. Trapè, S. Cotta, F. Giunta, A. Zumkeller y A. Vassallo).

56. Cfr. B. Lohse, Zur Eschatologie des alteren Augustin (De Civ. Dei 20, 9): Vigiliae Christianae 21 (1967) 221-240. 
mesas de Cristo constituyen para Agustín una unidad en cuanto pregunta y respuesta, es decir, una unidad en el marco de la dialéctica que las integra sin confundirlas. Por eso no se puede hablar de fideísmo, porque los interrogantes surgen de la entraña misma del hombre, mientras que las respuestas son ya un don de Dios mediante su Hijo, Jesucristo. Todo se orienta aquí hacia la resurrección y la felicidad y la justicia eternas, pero su único apoyo son las promesas de Cristo: en los libros 21 y 22 de «La Ciudad de Dios», en los que habla de las miserias de esta vida, de la mediación de Cristo, de los castigos eternos y de la resurrección, se aparta de todas las respuestas de los filósofos, incluidos Platón y el platónico Porfirio y de sus elucubraciones sobre la liberación total de la materia o cuerpo ${ }^{57}$, para refugiarse únicamente en la promesa de Cristo: credant esse facturum quod se facturum esse promissit ${ }^{58}$. Y a los que le preguntan qué harán los santos en aquel cuerpo espiritual, les responde lo que le dice la fe: non dico quod jam video, sed dico quod credo ${ }^{59}$.

Bajo esa misma perspectiva hay que contemplar la utopía política de S. Agustín en el libro 19 de «La Ciudad de Dios» en contra de la doctrina de Cicerón sobre el derecho (ius) y la república (res-publica).

Para un cristiano como Agustín, que vive profundamente la fe en la creación y en la redención, y que pone en la caridad cristiana la esencia de todas las relaciones sociales según el Evangelio, sólo puede haber una plasmación plena de la célebre justicia distributiva del derecho romano (unicuique suum: ¡a cada cual, lo suyo!), es decir: dar a Dios la propia persona, porque él la creó (Ib., XIX, 1: et qui seipsum aufert a dominanti Deo, a quo factum est). Ésa es la única verdadera justicia, y sin ella no puede haber ni derecho, ni pueblo, ni república. Agustín valora también los valores de la naturaleza humana y los valores y esperanzas de paz y de justicia de los pueblos sin distinción; sin embargo, como no ve en ellos plasmada de algún modo la utopía de la única verdadera justicia, no puede menos de desechar las definiciones de Cicerón y de Porfirio, sobre el derecho, la justicia, el pueblo y el bien común. No basta definir con Cicerón lo que es un pueblo: «una multitud de personas asociadas por el consentimiento del derecho y por el bien común: coetum multitudinis, juris consensu et utilitatis communione sociatum»; ni considerar a la autoridad como un bien para los súbditos porque los domina y ordena, del mismo modo que, según el estoico Cicerón, «Dios domina al hombre, el alma al cuerpo, la razón a la libido y demás partes viciosas del alma». No. Para Agustín sólo servir a Dios es útil para todos, porque sólo él es el bien común universal,

57. De civ. Dei XXII, 26.

58. De civ. Dei XXII, 25-26.

59. De civ. Dei XXII, 29, 2. 
así que no son justos los hombres que no obedecen a Dios, ni le aman y ofrecen el sacrificio de alabanza; así que, si no hay justicia en esos hombres, tampoco la puede haber en el conjunto de los mismos (in hominum coetu) que consta de tales hombres ${ }^{60}$.

Por eso Agustín, como siempre, atiende a la globalidad de la vida dirigida siempre por el amor y por el objeto del amor: un pueblo es «un conjunto de personas asociado por la comunión concorde de las cosas que ama» ${ }^{61}$. Hay que atender a lo que se ama, a la intención que dirige nuestras vidas y nuestras acciones, a las actitudes, según nos dicen los moralistas actuales. $\mathrm{Y}$ en este sentido, dice Agustín, ni Roma, ni Grecia, ni Egipto, ni Babilonia eran verdaderos pueblos y verdaderas repúblicas, porque no había en ellos la única verdadera justicia: obedecer a Dios y ofrecerle el sacrificio de alabanza exclusivo del Creador. Y tampoco puede hablarse en ellos de verdaderas virtudes, debido precisamente a esa falta de orientación de sus vidas y acciones, de sus motivaciones ocultas y orientadas hacia el egoísmo ${ }^{62}$.

Agustín ofrece nada más y nada menos que el Evangelio del amor social, el amor que da vida a la fe y a nuestras obras (Gál 5, 6; Sant 2, 17 y 26), para que se vaya cumpliendo más y más la verdadera justicia y se vaya adquiriendo la paz; esa paz, que no se da ahora más que en medio de la dialéctica de la virtud y de los vicios y las miserias, y por lo mismo es necesaria la oración a Dios «para pedirle la gracia de los méritos y el perdón de los pecados, y hay que darle gracias por los bienes recibidos». Sólo en la vida eterna será plena nuestra justicia, sin vicios ni corrupción; allí la obediencia a Dios será ya suavidad, facilidad, felicidad y paz (beatitudo pacis) ${ }^{63}$.

Es cierto que ya eran conocidos entonces diversos modelos de sociedad, tal como los describían Platón y Aristóteles, respectivamente en sus «Repúbli-

60. De civ. Dei XIX, 21, 1-2; «Et si in homine tali non est ulla justitia, procul dubio nec in hominum coetu, qui ex hominibus talibus constat» (Ib., XIX, 21, 2).

61. «Coetus multitudinis rationalis, rerum quas diligit concordi communione sociatus» (De civ. Dei XIX, 24).

62. De civ. Dei XIX, 24-25; Ib., XXII, 22-24; cfr. F.M. Tomás Ramos, o.c., en la n. 52 con la anotación de las principales cartas, p. 12: Ep. 18, 2; 91, 1, 1. 6; 104, 10;118, 15. 19. 20;130, 13. $14 ; 137,12.17 .20 ; 138,10.15 .17 ; 140,3.4 .63 .82 ; 153,3.12 .13 .16 .26 ; 155,1-2,9.13 .15 ; 185$, 19. $20 ; 220,11 ; 258,2-4$.

Si no se pierde de vista la utopía agustiniana de la «vera justitia», no se encontrará en Agustín ni una secularización del Estado al estilo moderno, ni mucho menos una teología constantiniana, como pretenden algunos autores: R.A. MARKuS, Saeculum: History and Society in the Theology of St. Augustine, Cambridge 1970; G.J. LAVERE, The Problem of the Common Good in Saint Augustine's «Civitas terrena»: Augustinian Studies 14 (1983) 1-10; H. CANCIK, Augustin als constantinischer Theologe, en «Religionstheorie und Politische Theologie», hrsg. Von J. TAUBES, Bd. 1. Der Fürst dieser Welt, München-Paderborn 1983, 136-152 (estudio cargado de freudianismo y otros prejuicios).

63. De civ Dei XIX, 27; Ib., XXII, 30. 
ca» y «Política»; Platón hablaba ya de la utopía del hombre justo y sabio (filósofo) para ejercer el poder. Y también es cierto que la herencia de la cosmovisión estoica, determinista y estática, dejó su huella en S. Pablo y en los Santos Padres, de tal modo que no se plantean, como lo hacemos hoy día, los cambios de estructuras para cambiar la sociedad: Todo poder viene de Dios, decía S. Pablo (Rom 13, 1), y «todo contribuye al bien de los llamados (Rom 8 , 28) ${ }^{64}$. Sin embargo, no se les puede acusar ni de servilismo político, ni de haber legitimado la esclavitud, como algunos les echan en cara sin cesar ${ }^{65}$; porque tanto S. Pablo en su Carta a Filemón, como toda la doctrina de S. Juan, reflejo fiel del Evangelio en general, tratan de renovar a las personas $\mathrm{y}$, mediante su conversión al seguimiento de Cristo, renovar a la sociedad.

Agustín lo dice expresamente en La Ciudad de Dios, XIX, al referirse a la paz doméstica de que habla el derecho romano, entre cuyos integrantes estaban los esclavos (servi). Se trata de cambiar por completo el substrato de las relaciones sociales, poniendo como única norma el amor cristiano, de tal modo que de hecho el señor (dominus) o paterfamilias, el que manda, se convierte en servidor y esclavo de aquellos a quienes manda: la pax domestica era en el derecho romano «la concordia en el mandar y en el obedecer de los que cohabitan»; pero para los cristianos hay un cambio radical: «Pues mandan a otros lo que tienen que proveerlos o mirar por ellos: el marido a la esposa, los padres a los hijos, los señores a los esclavos. Y obedecen aquellos a los que se provee: las mujeres a los maridos, los hijos a los padres, los esclavos a los señores. Pero en la casa del justo que vive de la fe y que peregrina aún hacia aquella ciudad celeste, los mismos que mandan sirven a aquellos a los que parecen mandar. Porque no mandan por el placer de dominar, sino por el deber de atenderlos; no por la soberbia de dominar, sino por la misericordia de mirar por su bien» ${ }^{66}$.

Para concluir, baste recordar que cuando una utopía, que es dinámica, animadora de la creatividad y la búsqueda y, por lo mismo de la esperanza, y que se mueve siempre en el ámbito de esa dialéctica vital entre el amor que crea y el egoísmo que destruye el bien común, según hemos visto ya con creces, cuando esa utopía es atrapada, objetivada y sacralizada de algún modo en unas estructuras fijas, ya sea la «Iglesia de cristiandad» medieval, la teología de nueva cristiandad, $u$ otros movimientos que absolutizan un modelo concreto de sociedad y lo identifican con el cristianismo, entonces la utopía pierde su

64. Cfr. M. Pohlenz, Die Stoa. Die Geschichte einer geistigen Bewegung, Göttingen 19592; E. Elorduy, El estoicismo, 2 vol., Madrid 1972; M. SPANNENT, Permanence du Stoicisme. De Zénon à Malraux, Gembloux 1973.

65. Cfr. R. GARAUDY, ¿Qué es la moral marxista?, Buenos Aires 1964, 11 ss.

66. De civ. Dei XIX, 14-15. 
carácter de tal utopía en esperanza, y generalmente se convierte en una dictadura de las conciencias y de las naciones. La misma utopía marxista del «comunismo» de Marx, del todo intramundana, al ser concretizada con violencia en un modelo de sociedad colectivista, como lo hizo Lenin en Rusia, se convierte en una dictadura de un solo partido con todo lo que esto trae consigo.

Nada más opuesto a la vida y a la mentalidad de S. Agustín, para quien la caridad y el servicio a los demás fue el lema de toda su vida. Lo triste ha sido que los cristianos han perdido con mucha frecuencia el sentido de esa utopía evangélica, esencial para el cumplimiento de la misión evangelizadora, o bien han identificado el cristianismo con algún modelo concreto de sociedad, cerrando así las puertas a la crítica profética y constructiva que han hecho los grandes santos como S. Agustín. Los que han identificado el Reino de Dios con los modelos de sociedad terrenos, han traído la barbarie en vez del Reino, según la acusación terrible de M. Horkheimer, que debería hacernos pensar ${ }^{67}$. Por eso, el Vaticano II repite con insistencia que los cristianos deben colaborar a la construcción de la ciudad terrena en comunión con todos los hombres de buena voluntad, pero sin caer en la tentación de identificar ninguna forma concreta de modelo social con el cristianismo y rechazando todo modelo que no respete los derechos fundamentales de la persona, en especial los derechos de los pobres y necesitados ${ }^{68}$.

Argimiro TURRADO, OSA

67. M. HoRKheImer, Sociedad en transición: estudios de filosofía social, Barcelona 1976; cfr. J.M. MARDONES, Esperanza cristiana y utopías intrahistóricas, Madrid 1983, 44ss.

68. Const. Gaudium et Spes, nn. 43, 58, 74-76. 